\title{
Autocuidado e vivências do envelhecer de cuidadores familiares de idosos: contribuições para enfermagem gerontológica
}

\section{Self-care and aging experiences of elderly's family caregivers: contributions to gerontological nursing}

\section{Autocuidado y experiencias al envejecer de cuidadores familiares de ancianos: contribuciones para la enfermería gerontológica}

Fernanda Vieira Nicolato

RESUMO: Objetivou-se compreender o autocuidado no processo de envelhecer de familiares que cuidam de idosos no domicílio. Pesquisa qualitativa do tipo exploratória. Participaram das entrevistas cinco familiares de idosos atendidos nas consultas de enfermagem em um ambulatório de Geriatria e Gerontologia. Utilizou-se análise de conteúdo que resultou em duas categorias: o envelhecimento do cuidador familiar de um idoso e a realização de seu autocuidado; e o reflexo do cuidar de idosos por um familiar em processo de envelhecimento. Compreendeu-se que, além da tensão do papel de cuidador, o familiar convive com problemas secundários ao próprio envelhecimento, por vezes, associados aos agravos crônicos. A condição de ter que cuidar associada a esses agravos influencia na dinâmica da vida do cuidador familiar. Os familiares compreendem quais são os requisitos universais de autocuidado, mas não conseguem exercê-los, pois priorizam o "ter que cuidar" do idoso sob sua responsabilidade. O estudo contribui para o processo de cuidar de famílias de idosos pelo enfermeiro, entretanto, apresenta limitações quanto ao quantitativo da população, o que aponta para necessidade de novas investigações com aprofundamento nos custos 1 Mestranda em Enfermagem pela Faculdade de Enfermagem da Universidade Federal de Juiz de Fora (UFJF. Pósgraduada na modalidade Lato Sensu- Residência de Enfermagem em Saúde do Adulto (2015). Graduada e Licenciada em Enfermagem pela UFJF (2013) Atua principalmente nos seguintes temas: consulta de enfermagem, autocuidado, educação em saúde e saúde da pessoa idosa. Universidade Federal de Juiz de Fora. Email: fernanda_nicolato_@, hotmail.com

2 Email: mila3907@yahoo.com.br

3 Email: ednabdecastro@hotmail.com 
sociais e financeiros que envolvam o processo de cuidar pela família de idosos no domicílio.

Palavras-Chave: Envelhecimento. Cuidadores. Cuidados de Enfermagem.

\begin{abstract}
: his study aimed to understand self-care in the aging process of family members who care for the elderly at home. It is a qualitative and exploratory research. The interview participants were five relatives of the elderly people's family attended in the nursing consultations of a Geriatrics and Gerontology outpatient clinic. The content analysis has been used and it resulted in two categories: aging of an elderly's family caregiver's and self-care; the reflex of caring for the elderly by a family member in the process of aging. It was understood that, in addition to the tension of the role of caregiver, the relative deals with secondary problems to the aging process itself, sometimes associated with chronic aggravations. The condition of having to care associated with these injuries, influences the life dynamics of the family caregiver. Family members understand the universal requirements for self-care, but are unable to exercise them, as they prioritize "having to care for the elderly" under their responsibility. The study contributes to the care of elderly's families by the nurse, however, it presents limitations on the quantitative population, which points to the need for new investigations with deepening social and financial costs that involve the care process by the elderly's family in the residence.
\end{abstract}

Key words: Aging, Caregivers, Nursing Care.

RESUMEN: Se objetivó comprender el autocuidado en el proceso de envejecimiento de familiares que cuidan ancianos en su domicilio. Investigación cualitativa de tipo exploratoria. Participaron en las entrevistas cinco familiares de ancianos atendidos en las consultas de enfermería de un ambulatorio de Geriatría y Gerontología. Se utilizó análisis de contenido que resultó en dos categorías: el envejecimiento del cuidador familiar de un anciano y la realización de su autocuidado; y el reflejo de cuidar ancianos por un familiar en proceso de envejecimiento. Se comprendió que, además de la tensión del papel del cuidador, el familiar convive con problemas secundarios al propio envejecimiento, a veces asociados a agravios crónicos. La condición de tener que cuidar asociada a esos agravios, influencia en la dinámica de la vida del cuidador familiar. Los familiares comprenden cuáles son los requisitos universales del autocuidado, pero no consiguen ejercerlos, pues priorizan el "tener que cuidar" al anciano bajo su responsabilidad. El estudio contribuye al proceso de cuidar familias de ancianos por el enfermero, sin embargo, presenta limitaciones en relación a lo cuantitativo de la población, lo que apunta a la necesidad de nuevas investigaciones con profundidad en los costos sociales y financieros que involucren el proceso de cuidar ancianos por la familia en su domicilio.

Palabras clave: envejecimiento; cuidadores; atención de enfermería.

\title{
INTRODUÇÃO
}

O envelhecimento populacional tem ocorrido de forma acelerada. De acordo com o IBGE ${ }^{1}$, o grupo de pessoas com 60 anos ou mais de idade terá aumento de forma acentuada, passando de 
13,8\%, em 2020, para 33,7\%, em 2060. A expectativa de vida dos brasileiros poderá aumentar de 73,17 anos, em 2009, para 81,29 anos, em 2050².

O envelhecimento acontece ao longo de toda a vida, mas as pessoas só percebem as mudanças quando estão perto dos 60 anos de idade, pois a meia idade é uma fase da idade adulta na qual as características desse processo se tornam mais evidentes ${ }^{3}$. A forma com que as pessoas percebem o processo de envelhecimento pode ter grande influência em como elas se cuidam no decorrer da vida $^{4}$.

As ações tomadas para promover, manter ou melhorar a saúde são embasadas na percepção do indivíduo sobre a própria condição e influenciam as escolhas diárias relativas às práticas de higiene, nutrição, exercícios, acessos aos cuidados de saúde e quaisquer outras atividades ${ }^{4}$.

A etapa da vida caracterizada como velhice, com suas peculiaridades, só pode ser compreendida a partir da relação que se estabelece entre os diferentes aspectos cronológicos, biológicos, sociais e psicológicos. Neste sentido, acredita-se que a velhice é difícil de ser definida, principalmente quando se almeja uma velhice saudável, a qual deve ser compreendida em sua totalidade ${ }^{5}$.

Com o aumento do número de idosos ocorre o crescimento do número de pessoas que irão cuidar destes idosos. Observa-se, assistematicamente, que os cuidadores familiares dos idosos passam, muitas vezes, por seu próprio processo de envelhecimento realizando a atividade de cuidar do familiar.

Sabe-se que o processo de cuidar, realizado pelo cuidador familiar no domicílio, é complexo, pois gera sobrecarga física, psicológica e isolamento social; falta de apoio institucional e da família, dificuldade com o ambiente/infraestrutura para realizar o cuidado e dificuldade financeira ${ }^{6}$. Esses fatores podem repercutir no processo de envelhecimento da pessoa que cuida, acarretando, por exemplo, doenças físicas, psicossomáticas, ansiedade, depressão e estresse ${ }^{7}$.

Estudos recentes ${ }^{8,9}$ têm evidenciado que as famílias não possuem conhecimento e/ou não podem contar com o suporte dos serviços de saúde para desempenhar o cuidado. Sendo a família o suporte necessário para o cuidado domiciliar ao idoso, torna-se importante que ela saiba lidar com as alterações advindas do envelhecimento e esteja ciente da necessidade de reorganização estrutural familiar, a fim de suprir as demandas do processo de cuidado, sem levar à sobrecarga do cuidador.

A assistência ao idoso, por vezes, tem por foco a qualidade do cuidado no domicílio sem, todavia, uma reflexão sobre as condições da família para assumir o cuidado. Assim, destaca-se a importância do desenvolvimento de políticas públicas que favoreçam a qualidade de vida dos cuidadores familiares.

Ao se refletir acerca do cuidado do familiar que cuida de um idoso e que se encontra em 
processo de envelhecimento, deve-se ter claro o conceito de autocuidado. Segundo Dorothea Orem $^{10}$, autocuidado é o desempenho de atividades para manutenção da vida, saúde e bem estar, realizadas pelo indivíduo em seu próprio benefício.

Orem ${ }^{10}$ apresenta três teorias interligadas: Teoria do Déficit de Autocuidado, Teoria dos Sistemas de Enfermagem e a Teoria do Autocuidado. A Teoria do Autocuidado expressa o que a autora traz como conceito de autocuidado, relacionando os fatores que interferem no mesmo. A Teoria do Déficit de Autocuidado aborda a relação de desequilíbrio entre a demanda de cuidados e a capacidade de uma pessoa em desempenhar tal demanda. A Teoria dos Sistemas de Enfermagem varia do Sistema totalmente compensatório, passando pelo Sistema parcialmente compensatório, até chegar ao Sistema de apoio-educação, modificando de acordo com a necessidade da Enfermagem em suprir a demanda terapêutica de autocuidado de um indivíduo ${ }^{10}$.

Os cuidadores, devido às suas atividades diárias de cuidado, podem ser incluídos no sistema de apoio-educação, pois necessitam desenvolver, juntamente com o enfermeiro, um plano de cuidados integral e individualizado, para que possam adquirir habilidades e conhecimentos que os ajudem a realizar o próprio autocuidado, ao mesmo tempo em que cuidam de um membro familiar dependente 9 .

A motivação inicial para esta pesquisa surgiu no desenvolvimento das consultas de enfermagem em um ambulatório multiprofissional de Geriatria e Gerontologia, na atuação como Residente de Enfermagem do Programa de Residência de Enfermagem em Saúde do Adulto e membro do Grupo de Estudos e Pesquisa sobre Autocuidado e Processo Educativo em Saúde e Enfermagem (GAPESE/CNPq), em que essa temática é discutida e publicações nesta área são realizadas.

No decurso das consultas de enfermagem ao idoso, pôde ser observado que os familiares cuidadores também apresentavam demandas para o cuidado de enfermagem, seja para ações referentes ao desenvolvimento do seu autocuidado, seja para a instrumentalização do processo cotidiano de cuidar de um idoso familiar.

Assim, frente ao exposto, a pesquisa teve como objetivo compreender o autocuidado no processo de envelhecer de familiares que cuidam de idosos no domicílio.

\section{METODOLOGIA}

Pesquisa qualitativa do tipo exploratória, cuja análise se orientou pela Análise de Conteúdo proposta por Laurence Bardin ${ }^{11}$ que a define como sendo:

Conjunto de técnicas de análise das comunicações visando obter, por procedimentos sistemáticos e objetivos de descrição do conteúdo das mensagens, indicadores (quantitativos ou não) que permitam a inferência de conhecimentos relativos às condições de produção/recepção (variáveis inferidas) destas mensagens ${ }^{11}$. 
Participaram da pesquisa, por meio da escolha por conveniência e tomando como referência os 90 idosos cadastrados no serviço, cinco cuidadores adultos que vivenciavam seu processo de envelhecimento e que atendiam aos critérios de inclusão. A pesquisa apresenta limitações em relação ao quantitativo da população, uma vez que foi estabelecido o mês de junho de 2014 para a seleção dos cuidadores nas consultas de enfermagem restringindo, assim, o número de participantes.

Os critérios de inclusão foram: a) Ser o cuidador familiar principal de um idoso no domicílio; b) Ser adulto em processo de envelhecimento, com idade compreendida entre 45-59 anos; c) Estar lúcido e residir no município sede da pesquisa; d) Ter participado da consulta de enfermagem no mês estabelecido para a seleção dos participantes da pesquisa, em junho de 2014.

A pesquisa foi desenvolvida em duas etapas: 1) No Ambulatório de Geriatria e Gerontologia do Hospital Universitário da Universidade Federal de Juiz de Fora, a fim de selecionar os participantes durante as consultas de enfermagem realizadas aos idosos; 2) Visitas domiciliares, em julho e agosto de 2014, visando a realizar as entrevistas semiestruturadas com os cuidadores familiares.

Após a primeira fase, realizou-se contato telefônico com os cuidadores familiares que atenderam aos critérios de inclusão, convidando-os a participar da pesquisa.

O anonimato dos participantes foi assegurado, uma vez que os entrevistados foram identificados por números, conforme a ordem das entrevistas (exemplo: E1, E2).

A investigação norteou-se pelos critérios estabelecidos pelas Diretrizes e Normas Regulamentadoras de Pesquisa Envolvendo Seres Humanos, constantes da Resolução no 466/2012, do Conselho Nacional de Saúde ${ }^{12}$. A coleta de dados ocorreu após aprovação do projeto no Comitê de Ética em Pesquisa do Hospital Universitário da Universidade Federal de Juiz de Fora, conforme parecer consubstanciado sob o número 519.179 de 24/02/2014, publicado na Plataforma Brasil.

A coleta de dados foi realizada nos meses de julho e agosto de 2014 durante visitas domiciliares aos cuidadores familiares. Adotou-se, para tal, um roteiro semiestruturado com as seguintes questões norteadoras: como o familiar cuidador de um idoso percebe seu processo de envelhecimento? E como se cuida enquanto vivencia o fato de "ter que cuidar" de um idoso no domicílio? Todas as entrevistas foram gravadas por meio de gravador comum.

As entrevistas foram transcritas e editadas com auxílio do Programa OpenLogos ${ }^{\circledR}$ versão 1.0.2 para interpretação, codificação e a triangulação dos dados ${ }^{13}$.

A exploração do material gerou 16 códigos relacionados à questão de investigação. Os códigos foram agrupados de acordo com suas semelhanças e cada grupo foi se constituindo em uma categoria para a pesquisa. Assim, a partir das etapas expostas, emergiram as duas categorias: 1) O envelhecimento do cuidador familiar de um idoso e a realização de seu autocuidado; e 2) O reflexo do cuidar de idosos por um familiar em processo de envelhecimento. 


\section{RESULTADOS E DISCUSSÕES}

O Quadro 1 apresenta a caracterização dos participantes da pesquisa.

QUADRO 1- Caracterização dos cinco familiares cuidadores de idosos no domicílio. Juiz de Fora- MG/2014

\begin{tabular}{|c|c|c|c|c|c|c|c|c|}
\hline $\mathbf{N}^{0}$ & Gênero & Tdade & $\begin{array}{l}\text { Tempo que } \\
\text { assumiu } \\
\text { o cuidado }\end{array}$ & $\begin{array}{c}\text { Estado } \\
\text { Civil }\end{array}$ & $\begin{array}{c}\text { Grau de } \\
\text { Parentesco } \\
\text { do Cuidador }\end{array}$ & $\begin{array}{c}\mathbf{N}^{0} \\
\text { Filhos }\end{array}$ & Escolaridade & $\begin{array}{c}\text { Profissão } \\
\text { Ocupação } \\
\text { atual }\end{array}$ \\
\hline E1 & $F$ & 59 & 3 & Casada & Esposa & 3 & Ensino Médio & Babá \\
\hline E2 & $\mathrm{F}$ & 59 & 4 & Divorciada & Sobrinha & 2 & Ensino Medio & $\begin{array}{l}\text { Empregada } \\
\text { Doméstica }\end{array}$ \\
\hline E3 & $\mathrm{F}$ & 43 & 1 & Casada & Filha & 2 & Ensino Médio & $\begin{array}{c}\text { Auxiliar de } \\
\text { Serviços } \\
\text { Gerais }\end{array}$ \\
\hline E4 & $\mathrm{F}$ & 59 & 4 & Casada & Esposa & 0 & $\begin{array}{c}\text { Ensino } \\
\text { Fundamental }\end{array}$ & Costureira \\
\hline & $\mathrm{F}$ & 57 & 2 & Separada & Filha & 3 & Ensino Medio & Diarista \\
\hline
\end{tabular}

Fonte: As autoras

Os participantes foram mulheres em sua totalidade, demonstrando a feminização dos cuidados desempenhado por familiares. Em estudos com cuidadores, observa-se que geralmente a mulher é quem desempenha as tarefas de cuidar em família, obedecendo às normas culturais, segundo as quais cabe a ela a organização da vida familiar e o cuidado dispensados aos filhos e aos idosos no papel de cuidadora ${ }^{8,9}$.

A idade prevalente da pesquisa foi de 59 anos, dado ao fato de os cuidados serem exercidos, em sua maioria, por cônjuge. Mas pode ser notado também o papel das filhas que, quando casadas, cuidam de suas casas e ainda cuidam de um idoso no domicílio. Na situação de cuidar do cônjuge ou dos pais existem questões afetivas profundas, arraigadas no relacionamento anterior do cuidador com o idoso e de ambos com o restante da família, além de questões práticas e financeiras que se misturam com as motivações afetivas ${ }^{14}$.

A quantidade de filhos apresentada reflete o declínio da taxa de natalidade da população brasileira e, consequentemente, um aumento no número de idosos. Para que uma população envelheça é necessário primeiro que haja uma queda da fertilidade, acompanhado de elevado crescimento relativo do contingente idoso, em face de um passado de alta fecundidade ${ }^{15}$.

O tempo em que se tornou responsável pelo cuidado tem estreita relação com o desgaste do papel do cuidador, pois quando assumido há um maior tempo, sendo na pesquisa o maior período de quatro anos, esse cuidador expõe-se a maiores condições de degastes. As dificuldades na execução das necessidades biológicas e psicossociais tais como dormir, descansar, momentos de lazer, são ainda mais visíveis com o passar do tempo, pois são essas condições que desencadeiam desgaste físico e mental, comprometendo a saúde ${ }^{16}$. 
Quanto ao grau de escolaridade dos cuidadores, quatro dos participantes possuem Ensino Médio, sendo esse fato diretamente relacionado às profissões por eles ocupadas, as quais não exigem um nível maior de instrução.

As dificuldades de acesso à educação eram bem maiores há décadas atrás quando comparadas com a atualidade, principalmente no que se refere às mulheres ${ }^{17}$. As futuras gerações de idosos atingirão níveis mais altos de educação formal do que a população atual, sendo consumidores de saúde melhor informados ${ }^{18}$. O nível de escolaridade influencia diretamente em seu processo de cuidado, sendo que os indivíduos escolarizados procuram mais por cuidados de saúde e bemestar $^{18}$. Sendo assim, poderá haver melhoria nos indicadores de saúde, pois as pessoas serão mais exigentes quanto à qualidade dos atendimentos e se cuidarão com mais eficiência.

\section{O envelhecimento do cuidador familiar de um idoso e a realização de seu autocuidado}

A primeira categoria aborda as modificações do processo de envelhecimento na vida dos cuidadores familiares e como essas mudanças podem interferir no cuidado ao idoso e, consequentemente, em seu autocuidado.

As alterações relacionadas ao envelhecimento são consideradas um processo natural que se desencadeia com o passar do tempo. A fase biológica, surgindo com as alterações corporais são, principalmente, as mais visíveis e manifestam-se em primeiro lugar.

O sistema tegumentar, o qual inclui pele, pelos e unhas, passa por alterações significativas e, como são visíveis, as alterações nesse sistema são as mais óbvias e evidentes tanto para o indivíduo que envelhece como para as outras pessoas ${ }^{4}$. A concepção dos cuidadores acerca de seu processo de envelhecimento pode ser observada abaixo.

Ah, a gente vai notando as modificações pela aparência. Como posso dizer, pelo corpo, o rosto enrugado, os cabelos que estão ficando brancos, aí já vejo a diferença (E1).

Agora, com relação ao físico, é o cabelo, são as rugas, a flacidez da pele... (E2).

De acordo com Eliopoulos ${ }^{18}$, o envelhecimento leva a diversas alterações no corpo humano: os cabelos branqueiam e ressecam, os dedos flexíveis e retos encurvam e ficam doloridos, alteram-se os contornos do corpo e diminui a altura. Com o envelhecimento essas alterações são esperadas, mas é importante que o enfermeiro tenha conhecimento e saiba distinguir as alterações advindas com o processo de envelhecimento.

A gente fica mais lenta para fazer as coisas, assim, para interagir com as coisas, para fazer uma limpeza. Quando a gente era mais nova, a gente tinha mais agilidade, com certeza. Além disso, ainda sinto que a minha perna que tá me atrapalhando um pouco, porque dói um pouco, tenho que caminhar pouco, andar pouco (E4). 
A casa, a gente se vira, tem hora que eu passo por cima, faço mais as coisas para dar atenção a ele, as coisas para ele, como se diz assim, de mais urgência né, porque é muita coisa (E1).

Diante disso, o enfermeiro deve estar atento às alterações físicas que estão propensas a ocorrer no processo de envelhecimento desses cuidadores, de modo a avaliá-los durante a consulta de enfermagem e visitas domiciliares, para determinar a extensão das mudanças ocorridas, a fim de elaborar um plano de cuidados em resposta às necessidades específicas desses indivíduos ${ }^{4}$.

Com o aumento dos anos vividos, as experiências se transformam em maturidade na concepção dos participantes, que a consideram como favorável, pois os tornam mais capazes de enfrentar a vida e agrega motivação para viver melhor.

Muda tudo, muda pensamento muda corpo, o modo de pensar. Já sinto mais preparada para enfrentar a realidade, mais madura para ver o mundo e isso é muito bom porque você se sente segura (E5)."

Mesmo conseguindo observar os pontos positivos do envelhecimento, ele ainda é visto pelos participantes como uma fase de declínio, em que poucos são os benefícios e aquisições às quais se podem desfrutar.

Analisa-se pelas falas que a concepção do que é ser velho está relacionada às mudanças negativas trazidas com o aumento da idade, podendo-se notar entre os participantes o receio de envelhecer, exemplificado com manifestações de repulsa à lembrança do dia do aniversário.

Percebo que estou envelhecendo porque os anos vão passando, a gente vê tanta coisa que acontece com tudo, aí a gente pensa: "Ai meu Deus, eu estou chegando lá". Eu não quero chegar lá não. No meu aniversário vocês não fazem nada não, porque eu não quero saber que estou ficando velha não (E5).

A sociedade atual valoriza essencialmente a juventude, mesmo sabendo que envelhecimento é um processo normal e que afeta a todos os seres humanos e, tendo uma visão negativa deste período da vida, faz com que os próprios idosos detenham esta imagem, o que constitui um dos significados preconcebidos sobre a velhice ${ }^{19}$.

A forma como as pessoas se cuidam no decorrer da vida influencia em como percebem seu processo de envelhecimento ${ }^{4}$. A prática educativa, no contexto da atenção primária, aparece como fator positivo, contribuindo para a consolidação de espaços de troca de experiências e de informações, permitindo o desenvolvimento de habilidades de interação social como dança, grupos de convivência, de produção de artesanatos e passeios programados ${ }^{20}$.

Aqui na igreja tem alongamento, eu fui uma vez só. Faço acompanhamento lá no instituto da mulher, mamografia e preventivo, já participei de grupos para a saúde da mulher (E1). 
Eu já participei de grupo da mulher, eu tenho até o cartão do Instituto da Mulher, de ano em ano eu vou no ginecologista, assim eu cuido (...) Faço caminhada, mesmo que pouco, mas faço (E4).

Existe uma preocupação por parte dos participantes pela busca de qualidade de vida e bemestar, mas essas ações ainda não são implantadas na Unidade de Atenção Primária à Saúde (APS) de seus bairros, mas sim em outros pontos da Rede de Atenção à Saúde, como os ambulatórios especializados. Os serviços devem ser capazes de dar suporte a indivíduos independentes, para que mantenham a capacidade de autocuidado e para que possam evitar problemas físicos, emocionais, sociais e espirituais ${ }^{18}$.

As ações no campo da enfermagem gerontológica podem ser desenvolvidas pelos enfermeiros em busca de um melhor envelhecimento, tais como: a prática de exercícios físicos, a alimentação adequada, mudanças no hábito de vida, busca por atividades de promoção da saúde e de prevenção de patologias crônicas. O exercício regular deve constituir parte do plano diário, pois pode ajudar a conservar a flexibilidade das articulações, manter a massa muscular, controlar os níveis da glicose sanguínea e o peso, e promover uma sensação de bem-estar ${ }^{4}$. No Brasil, as Doenças Crônicas Não Transmissíveis (DCNT) constituem um problema de saúde de grande magnitude e correspondem a $72 \%$ das causas de mortes, destacando-se as doenças do aparelho circulatório, câncer, diabetes e doença respiratória crônica. Atingem pessoas de todas as camadas socioeconômicas e, principalmente, aquelas pertencentes a grupos vulneráveis, como os idosos e os de baixa escolaridade e renda ${ }^{21}$.

A alimentação adequada e balanceada, a prática regular de exercícios físicos, a busca por atividades prazerosas que reduzam o estresse, a diminuição dos danos decorrentes de consumo de álcool e do tabaco, a diminuição significativa da automedicação e convivência social estimulante podem reduzir essas mortes por doenças evitáveis ${ }^{(15 ; 22)}$.

De acordo com a VI Diretriz Brasileira de Hipertensão ${ }^{23}$, em 2001, cerca de 7,6 milhões de mortes no mundo foram atribuídas à elevação da pressão arterial (PA), 54\% ao acidente vascular encefálico (AVE) e 47\% à doença isquêmica do coração (DIC), sendo a maioria em países de baixo e médio desenvolvimento econômico e mais da metade em indivíduos entre 45 e 69 anos. Em nosso país, as doenças cardiovasculares (DCV) têm sido a principal causa de morte.

Diante disso, os cuidadores familiares estão expostos ao risco do desenvolvimento de patologias e agravos e, o fato de ser cuidador, pode ser um agravante a sua saúde, pois deixam seu autocuidado em segundo plano. Alguns fatores de risco podem ser prevenidos e cabe ao enfermeiro ações de prevenção destes riscos, dando suporte ao cuidador no cuidado ao idoso e facilitando a prática do desenvolvimento de seu autocuidado.

Percebe-se, no trecho da fala de E5, a preocupação em se tornar dependente quando envelhecer 
e, para que isso não ocorra, ela busca por ações que irão proporcionar qualidade de vida na velhice.

(...)E assim agora eu sei que para não ficar um idoso dependente eu preciso fazer uma ginástica, assim até que saúde eu já estou começando a me cuidar porque assim, é daqui que eu tenho que começar a fazer alguma coisa para eu não ter uma velhice muito ruim... Vou procurar não ser caquética para não dar trabalho para os outros (E5).

Quando se fala em envelhecimento saudável ou bem-sucedido, os profissionais da saúde têm suas definições sobre o assunto, mas é importante levar em conta a forma com que esses indivíduos definem o envelhecimento ideal e como consideram a possibilidade de alcançar esse envelhecimento ${ }^{4}$.

Os cuidadores expressam a preocupação de se tornarem dependentes e, para que isso não ocorra, buscam um envelhecimento ativo e saudável. Essa preocupação vem associada a um sentimento de dúvida, no caso de precisarem de um cuidador, se teriam alguém para ajudá-los.

Eu tenho muita preocupação, eu espero que meus filhos me ajudem, mas se eu tenho preocupação eu tenho. Eles trabalham fora, quase nem tem tempo para pai e mãe... Quando eu preciso de alguma coisa minha filha me ajuda, mas está sempre reclamando também que não tem tempo. Vai ser difícil, vai ser difícil (E1).

Mesmo que nas falas eles expressem essa incerteza, já é assegurada, na Constituição Federal de 1988, a responsabilidade da família no cuidado com o idoso, em seu Art. 230: "A família, a sociedade e o Estado têm o dever de amparar as pessoas idosas, assegurando sua participação na comunidade, defendendo sua dignidade e bem-estar e garantindo-lhes o direito à vida" ${ }^{24}$.

O apoio da família traz um conforto aos cuidadores e a falta dele pode gerar insegurança. Mas esse apoio deverá ser encontrado nos profissionais da saúde, o que seria de extrema relevância para esse cuidador, despertando um sentimento de segurança diante das ações de assistência oferecida. O enfermeiro, principalmente o da APS, deve ser o profissional de referência para esse cuidador, de modo que encontre apoio para a promoção de seu envelhecimento e de seu autocuidado.

Existem vários fatores que influenciam o autocuidado, sendo o fato de cuidar de um idoso no domicílio um dificultador para esta prática, pois ocorrem várias mudanças no cotidiano do cuidador familiar. $\mathrm{O}$ fato de ter que cuidar de um idoso gera uma sobrecarga para o cuidador que, muitas vezes, deixa de fazer para si por ter que fazer pelo outro.

A mudança nas atividades cotidianas, somada à realização dos cuidados do familiar dependente, acaba sobrecarregando o cuidador que pode apresentar cansaço físico, depressão, 
abandono do trabalho, alterações na vida conjugal e familiar, o que prejudica não só a ele próprio, mas também a pessoa a ser cuidada ${ }^{25}$.

A sobrecarga do cuidador foi observada entre os cuidadores familiares de idosos, os quais demonstraram não saber como administrar essas alterações na vida diária.

Tem hora que eu acho que não vou dar conta. Sabe assim, é muita coisa. Tem hora que eu, que eu necessito de uma ajuda, de uma ajuda para cuidar dele, porque tem hora que eu me sinto sozinha, sozinha assim (E1).

Há sempre uma sobrecarga indiscutível. Quando você cuida de idoso é sempre uma sobrecarga, eu sempre falo isso (E2).

Pode-se apreender a falta de auxílio por outros familiares nas demandas de cuidados com o idoso, em especial enfatiza-se a ausência de revezamento nas atividades de cuidado entre os familiares. Os cuidadores familiares se dedicam de modo permanente sem o auxílio de outros familiares na divisão das tarefas rotineiras. No entanto, o enfermeiro deve realizar um planejamento de ações direcionadas ao apoio das famílias, tendo como objetivo minimizar os níveis de sobrecarga, promovendo um ambiente que atenda às necessidades do idoso e dos familiares, contribuindo para o estabelecimento de uma boa dinâmica intrafamiliar .

Dentre as dificuldades apontadas pelos cuidadores está o acúmulo de atividades domésticas e o fato de ter que cuidar do idoso. Relatam que os cuidados com a casa e as suas atribuições relacionadas aos cuidados diretos com o idoso geram um acúmulo de trabalho e, possivelmente, contribuem com os elevados níveis de sobrecarga e desconforto emocional.

Assim ela me quer sempre por perto. Quando ela precisa, ela me tem como referência, aí muitas vezes não sobra tempo para eu me cuidar. Eu preciso ficar sempre com ela para fazer tudo dela (E3).

As alterações no cotidiano do cuidador trazem influências para sua saúde, pois as rotinas não são mais as mesmas quando se tem alguém que precisa do seu cuidado.

O envolvimento dos familiares com as atividades e demandas de cuidado, somados ao exercício de tarefas domésticas e as demais responsabilidades familiares, fazem com que os cuidadores negligenciem o seu autocuidado e o cuidado com as próprias condições de saúde?

Ao relatar sobre o seu cotidiano, o cuidador familiar coloca em evidência as suas dificuldades na realização do autocuidado, sendo a falta de tempo a justificativa mais frequente.

Eu preciso tomar meu banho correndo, porque aí ela fica sozinha me chama toda hora, tudo que faço para mim preciso fazer rápido (E2).

Sinto, sinto sim, eu não tenho muito tempo de me cuidar não (E1). 
O que pode ser observado é que estes cuidadores não conseguem executar com qualidade os requisitos universais de autocuidado por deixarem essas atividades em segundo lugar em suas vidas, tendo como prioridade o cuidado do outro.

A "tensão do papel de cuidador" inclui-se entre os diagnósticos de enfermagem, sendo identificado como "estado em que o indivíduo está apresentando sobrecarga física, emocional, social e/ou financeira no processo de cuidar de outra pessoa" 26 .

O déficit na realização do autocuidado do cuidador está relacionado às dificuldades em conciliar o autocuidado com as atividades de cuidado do familiar ${ }^{10}$. Essas situações indicam a necessidade de ações de apoio ao familiar cuidador e de educação em saúde, desenvolvidas pela enfermagem e pela equipe multiprofissional, que proporcionem melhores condições de cuidado para população idosa dependente, e que atenda as especificidades de conhecimentos e habilidades necessárias ao familiar cuidador, para desempenhar o papel a ele delegado.

Os enfermeiros devem ser capazes de reconhecer as dificuldades específicas do indivíduo e o grau de limitação do autocuidado para que intervenções de enfermagem apropriadas sejam planejadas ${ }^{4}$. Fica evidente a importância da implantação de grupos educativos, as visitas domiciliares e, além disso, o desenvolvimento da consulta de enfermagem seja em nível de atenção primário ou secundário, visando atender às demandas dos cuidadores.

\section{O reflexo do cuidar de idosos por um familiar em processo de envelhecimento}

O cuidar é uma condição inerente ao ser humano, mas, quando esse cuidado precisa ser desenvolvido para si e para outra pessoa, ele pode se tornar um desafio.

A função do cuidador é acompanhar e auxiliar a pessoa cuidada, fazendo por ela somente aquilo que ela não consiga fazer sozinha, não fazendo parte de sua rotina técnica e dos procedimentos característicos de profissões legalmente estabelecidas, particularmente na área de enfermagem ${ }^{25}$. E pelos relatos dos cuidadores pôde-se perceber que não encontraram apoio nos serviços de saúde e, muitas vezes, precisaram desempenhar papéis que não estavam preparados. A falta de apoio, principalmente da APS, ocasiona um sentimento de insegurança.

Na parte de medicamento essas coisas assim a gente consegue... (E1).

Aqui só tem médico, remédio, assim quando precisa tem, mas só isso, se eu precisar de outra coisa não tem... (...) Para cuidar dela só recebemos medicação (E3).

Observa-se, pelos relatos, que as ações ofertadas na APS são restritas, sendo, na maioria dos casos, distribuição de medicação, aferição de PA e consultas médicas. As ações devem ter em vista o princípio da integralidade, em que as ações de promoção, prevenção, tratamento e reabilitação façam parte do cuidado. 
O apoio do Sistema de Saúde brasileiro em todos os seus âmbitos: atenção primária, secundária e terciária; assim como o cuidado de enfermeiros, seja por orientações por meio de práticas educativas, seja pelo apoio por meio de outras estratégias de cuidados, contribui com o cuidado.

Com a Atenção Domiciliar (AD), a rede de assistência se complementa, possibilitando a continuidade do cuidado no domicílio do indivíduo, garantido assistência integral e resolutiva no processo saúde-doença ${ }^{27}$.

Os cuidadores relataram como forma de atendimento prevalente as consultas médicas, como pôde ter sido notada nas falas anteriores e nas que se seguem, o que remete ao pensamento conservacionista do atendimento médico centrado.

Olha, aqui pelo menos, no posto aqui, na nossa rua, quando a gente precisa a gente tem um bom cuidado, a gente tem um médico muito bom, pediatra também, ginecologista se precisar (E3).

Observa-se que, quando os familiares relataram precisar de atendimento, eles tinham a assistência médica como referência. Esse fato nos faz refletir sobre o papel da equipe multiprofissional nas APS e como componente desta equipe, o enfermeiro.

Lá tem enfermeira sim, mas eu nunca passei por atendimento com ela não, nem consulta nem nada não (E2)

(...)a não ser com relação a uma feridinha que tem uma enfermeira que olha lá, sabe (E3).

Os cuidadores mostraram ter forma limitada de conhecimento sobre as ações de enfermagem exercida no âmbito da APS, principalmente no que se refere às ações de promoção e prevenção, que são fundamentais nesse nível de atenção.

Os grupos educativos, quando realizados pelos enfermeiros aos cuidadores, podem proporcionar alívio, diminuição dos sentimentos de sobrecarga e desconforto emocional além de promover o seu bem estar, pois o cuidador percebe que não está sozinho, vê que as dúvidas e dificuldades não são só suas, que suas experiências podem ser valiosas para outros cuidadores e, assim, podem formar uma rede de apoio entre eles ${ }^{25}$.

Apesar de todas as dificuldades encontradas na organização e no apoio dos serviços de saúde, os participantes levantaram como fator importante a falta de capacidade de atendimento dos profissionais da saúde em relação às especificidades desse grupo populacional. Os profissionais da saúde ainda não se encontram capacitados para o atendimento aos idosos e isso foi notado pelas falas da maioria dos participantes, nas quais se observou a existência de uma insatisfação em relação aos atendimentos realizados nas APS.

Acho que têm alguns profissionais que são 'meio rudes', não falam com a gente 
direito, nem perguntam, só querem saber o que você tem e pronto, dá um remedinho e pronto e acabou, num quer saber direito, alguns acho que não está preparado não, meu ponto de vista (E3).

A gente não vê muita preocupação por parte dos profissionais não, são poucos que realmente se preocupam com o idoso... (E2).

Em 2006, por meio da Portaria $n^{0}$ 399, foi divulgado o Pacto pela Saúde, o qual possui três eixos: o Pacto em Defesa do SUS, o Pacto de Gestão do SUS e o Pacto pela Vida. Este tem como prioridades e responsabilidades a população idosa. A Saúde do Idoso tem como finalidade algumas metas, dentre elas: a formação e educação permanente dos profissionais de saúde do SUS na área de saúde da pessoa idosa; divulgação e informação sobre a Política Nacional de Saúde da Pessoa Idosa para profissionais de saúde, gestores e usuários do SUS ${ }^{28}$. A partir deste contexto, observa-se a importância de ter profissionais capacitados para atender as especificidades da população idosa. Os familiares entrevistados encontram dificuldades no percurso de busca por auxílio na assistência ao idoso, pois, apesar de todo empenho dispensado, esses cuidadores familiares não podem contar com a ajuda de outros familiares, nem dos serviços de saúde e dos profissionais da saúde, que são ditos como impasses para um cuidado de qualidade.

Aqui o posto ajuda muito pouco, médico deve ter uns 3 a 4 anos que não consulto aqui, porque a gente nem consegue marcar, tem que levantar 2 horas da manhã para conseguir marcar, eu não vou fazer isso $(\mathrm{E} 4)$.

A gente tem dificuldade de marcar médico, não tem, a gente tem que ir para a fila esperar como todo mundo. E, às vezes, ele tem que ir junto, e chega lá ele não tem muita paciência, por causa da doença dele... (E1).

Dentre as prioridades advindas do Pacto Pela Saúde, na Saúde da Pessoa Idosa, deve-se respeitar o acolhimento preferencial em unidades de saúde, respeitado o critério de risco ${ }^{28}$. Não é essa a realidade encontrada pelos familiares, o que é um fator preocupante, pois a doença na pessoa idosa é um fator de risco considerável, sendo necessário atendimento prioritário para esta faixa etária.

Os cuidadores familiares mostraram-se preocupados em face da dificuldade de acesso aos serviços de saúde, da piora do quadro clínico e de possíveis reinternações, já que é mais prevalente nesta faixa etária, devido aos fatores que se agregam à idade. O declínio nas condições clínicas de saúde desses idosos leva a maior sobrecarga dos cuidadores, visto que o idoso irá demandar maiores cuidados no domicílio ou de um acompanhante enquanto vivencia um período de internação.

Que aí com a experiência que a gente tem, que eu tenho, eu sei perfeitamente que a cada internação é uma decaída e aí a condição vai ficando realmente terrível, até entrar na fase vegetativa, que ai realmente é uma fase muito dolorosa (E2). 
Frente a esta situação, surge a necessidade de se pensar uma estratégia para melhorar a organização do serviço e assistência ao idoso de forma sistematizada, integral e de acordo com suas peculiaridades, intervindo de forma a prevenir agravos à saúde e auxiliar o indivíduo em toda a longevidade, minimizando fragilidades que vão interferir na independência e autonomia, refletindo na autoestima e na qualidade de vida.

Uma das metas do Programa Nacional de Saúde da Pessoa Idosa (PNSPI) é aumentar a qualidade dos serviços oferecidos pelo SUS para trabalhar com os detalhes da vida da pessoa idosa ${ }^{29}$. Quando os idosos e seus cuidadores conhecem seus direitos, essas dificuldades podem ser amenizadas, pois tendem a ir em busca deles.

Também o idoso tem suas leis, eles sabem, vai falar alguma coisa com idoso para ver se ele não sabe... Vê a minha mãe, ela deve saber mais do estatuto do idoso do que eu (E5).

Diante de todas as políticas públicas para a pessoa idosa ainda são poucos os que realmente a conhecem. Dentre as prioridades do Pacto da Pessoa Idosa tem-se a importância da divulgação e informação sobre a Política Nacional de Saúde da Pessoa Idosa para profissionais de saúde, gestores e usuários do SUS ${ }^{29}$. Quando relataram conhecer seus direitos, expressaram sentimentos positivos, pois tinham mais segurança e se sentiam no direito de serem assistidos.

O enfermeiro deve ser capaz de contribuir com o cumprimento dos direitos de assistência aos cuidadores e aos idosos e de influenciar na elaboração e implementação de políticas públicas que visem a um atendimento resolutivo e humanizado, de modo que contribua para que os cuidadores desfrutem de um envelhecimento independente e de qualidade.

\section{CONCLUSÃO}

O cuidador que se encontra em processo de envelhecimento e realiza a atividade de cuidar de um idoso no domicílio merece um cuidado especial. É importante o desenvolvimento de ações de saúde voltada para essa população, de modo que contribua para um envelhecimento ativo e saudável, além de auxiliar no cuidado do idoso e evitar a sobrecarga do cuidador.

Dentre as ações de enfermagem deve-se salientar a educação para a saúde, que precisa ser desenvolvida, seja na atenção primária, por meio de visitas domiciliares e realização de grupos educativos, seja na atenção secundária, pela realização de consultas ambulatoriais, em que a equipe multiprofissional, em especial o enfermeiro, deve aproveitar a oportunidade de ensinar e esclarecer dúvidas dos idosos e de seus familiares, seja na atenção terciária, na preparação do paciente e familiar durante toda a internação para o momento da alta.

O estudo contribui para o processo de cuidar de famílias de idosos pelo enfermeiro e ressaltase, além disso, o valor de despertar nos profissionais das equipes multiprofissionais de Atenção Domiciliar para incluir atenção e cuidado ao cuidador familiar. 
Apesar das limitações apresentadas por esta pesquisa quanto ao quantitativo da população, seu caráter exploratório, frente a uma temática ainda pouco conhecida, identificou-se a necessidade de novas investigações com aprofundamento nos custos sociais e financeiros que envolvam o processo de cuidar pela família de idosos no domicílio.

\section{REFERÊNCIAS BIBLIOGRÁFICAS}

1. Instituto Brasileiro de Geografia e Estatística. Ministério do Planejamento, Orçamento e Gestão. Projeção da população do Brasil por sexo e idade para o período 2000-2060: revisão 2013. Instituto Brasileiro de Geografia e Estatística. Brasília: 2013.

2. Instituto Brasileiro de Geografia e Estatística. Ministério do Planejamento, Orçamento e Gestão. Observações sobre a evolução da mortalidade no Brasil: o passado, o presente e perspectivas. Instituto Brasileiro de Geografia e Estatística.Brasília: 2010.

3. Teixeira AC, Barbosa RSP. Avaliações psicossociais de adultas na meia idade. BolInfUnimotrisaudeSociogerontol. 2011;2(1):56-73.

4. Wold G. Enfermagem Gerontológica / Glória Hoffmann Wold. Tradução Ana Helena Pereira Correa et al. Rio de Janeiro: Elsevier; 2013.

5. Freitas MC, Queiroz TA, Souza JAV. O significado da velhice e da experiência de envelhecer para os idosos. Rev. escola de enferm. USP. 2010;2:407-412.

6. Floriano LA, Azevedo RCS, Reiners AAO, Sudré MRS, et al. Care performed by family caregivers to dependent elderly, at home, within the context of the family health strategy. Texto contexto enferm. 2012;3:543-548.

7. Anjos KF. Qualidade de Vida de Cuidadores Familiares de Idosos Dependentes no Domicílio. Texto contexto enferm. 2014;3:600-608.

8. Couto AM, Castro EAB, Caldas CP. Vivências de ser cuidador familiar de idosos dependentes no ambiente domiciliar. Rev Rene. 2016;1:76-85.

9. Costa SRD, Castro EAB. Autocuidado do cuidador familiar de adultos ou idosos dependentes após a alta hospitalar. Rev Bras Enferm. 2014;6:979-86.

10. Orem DE. Nursing: concepts of practice 5ed. St. Louis(US): Library of Congress; 1995.

11. Bardin L. Análise de conteúdo. Edições 70. 2011.

12. Ministério da Saúde (BR). Resolução 466, de 12 de dezembro de 2012: diretrizes e 
normas regulamentadoras de pesquisa envolvendo seres humanos. Diário Oficial da República Federativa do Brasil, Brasília: 2012.

13. Camargo Júnior KR. Apresentando Logos: um gerenciador de dados textuais. Rio de Janeiro: Instituto de Medicina Social - UERJ; 2003.

14. Santos AA, Pavarini SCI. Perfil dos cuidadores de idosos com alterações cognitivas em diferentes contextos de vulnerabilidade social. Revista Gaúcha de Enfermagem. 2010;1:115122.

15. Ministério da Saúde (BR). Secretaria de Atenção à Saúde. Departamento de Atenção Básica. Caderno de Atenção Básica no 36: Estratégia para o Cuidado da Pessoa com Doença Crônica: Diabetes Mellitus, Brasília, 2013b.

16. Santos SMA. Idosos, família e cultura: um estudo sobre a construção do papel de cuidador. 3 ed. Campinas: Alínea; 2010.

17. Ferreira OGL, Maciel SC, Costa SMG, Silva AO, Moreira MASP. Envelhecimento ativo e sua relação com a independência funcional. Texto contexto enferm. 2012;3:513-518.

18. EliopoulosC. Enfermagem gerontológica. 7. ed. Porto Alegre: Artmed; 2011.

19. Freitas MC, Queiroz TA, Souza JAV. O significado da velhice e da experiência de envelhecer para os idosos. Rev. escola de enferm. USP. 2010;2:407-412.

20. Flisch TMP, Alves RH, Almeida TAC, Torres H, Schall VT, Reis DC. Como os profissionais da atenção primária percebem e desenvolvem a Educação Popular em Saúde?. Interface (Botucatu). 2014;18: 1255-1268.

21. Ducan BB et al. Doenças Crônicas Não Transmissíveis no Brasil: prioridade para enfrentamento e investigação. Rev Saúde Pública. 2012;46(Supl):126-34.

22. Ministério da Saúde (BR). Secretaria de Atenção à Saúde. Departamento de Atenção Básica. Caderno de Atenção Básica n ${ }^{\circ}$ 15. Estratégia para o Cuidado da Pessoa com Doença Crônica: Hipertensão Arterial Sistêmica. Brasília, 2013.

23. Sociedade Brasileira de Cardiologia / Sociedade Brasileira de Hipertensão/ Sociedade Brasileira de Nefrologia. VI Diretrizes Brasileiras de Hipertensão. ArqBrasCardiol, 2010;95:151

24. Ministério da Saúde (BR). Constituição da República Federativa do Brasil de 1988. Diário Oficial da União. Brasília, 1988. 
$186 / /$

25. Ministério da Saúde (BR), Secretaria de Atenção à Saúde, Secretaria de Gestão do Trabalho e da Educação na Saúde. Guia prático do cuidador. Brasília: 2008.

26. NANDA. Diagnósticos de enfermagem da NANDA: definições e classificação-2009-2011. Porto Alegre: Artmed; 2010.

27. Ministério da Saúde (BR). Secretaria de Atenção à Saúde. Departamento de Atenção Básica. Caderno de atenção domiciliar vol. 2 /Programa Melhor em Casa. Brasília, 2013.

28. Ministério da Saúde (BR). Portaria n. 399/GM de 22 de fevereiro de 2006: Divulga o Pacto pela Saúde 2006, Brasília: 2006.

29. Ministério da Saúde (BR). Secretaria de Atenção à Saúde. Departamento de Atenção Básica. Envelhecimento e saúde da pessoa idosa. (Série A. normas e Manuais Técnicos) (Caderno de Atenção Básica no 19), Brasília: 2006.

Artigo apresentado em 13/04/2017

Artigo aprovado em 26/07/2017 Artigo publicado no sistema em 20/09/2017 